\title{
Regenerative medicine: could Parkinson's be the first neurodegenerative disease to be cured?
}

\author{
Mariacruz L Díaz*,1 \\ ${ }^{1}$ Instituto Nacional de Investigación y Tecnología Agraria y Alimentaria (INIA), Departamento de Reproducción Animal, Madrid \\ 28040, Spain \\ *Author for correspondence: Tel.: +034 913473 757; lopez.maria@inia.es
}

Parkinson's disease is one of the most insidious neurodegenerative diseases in developed countries. Today, human pluripotent stem cells are produced from embryonic or adult cells, multiplied, differentiated into neural cell lines and ultimately transplanted into disease animal models or patients. Nowadays, DOPAminergic neurons derived from human pluripotent stem cells and human parthenogenetic cells are being clinically tested in China and Australia, respectively. More importantly, good manufacturing practices have been developed and the neurons obtained have been successfully tested in nonhuman primates by teams in Europe, USA and Japan. However, there is a need for translational clinical studies with small molecules tested in vitro, as well as testing of the the efficacy of additional therapies.

Lay abstract: The high prevalence of sporadic cases of Parkinson's disease is a serious health problem in developed societies. A safe regenerative therapy is urgently needed, and is among the most promising treatments. In several years, we can expect to see results from clinical studies using stem cells from across the globe. It is probable that the definitive cure will require more than one therapeutic approach, as discussed in this review.

First draft submitted: 7 June 2018; Accepted for publication: 20 August 2019; Published online:

10 October 2019

Keywords: clinical trials $\bullet$ DOPAminergic precursors $\bullet$ glycobiology $\bullet$ human embryonic SC $\bullet$ human induced pluripotent $\mathrm{SC} \bullet$ human parthenogenetic neural SC $\bullet$ human pluripotent $\mathrm{SC} \bullet$ neurodegeneration

- Parkinson's • prion-like diseases $\bullet$ regenerative medicine 


\section{Graphical abstract:}

\section{Reduction of prion-like proteins}

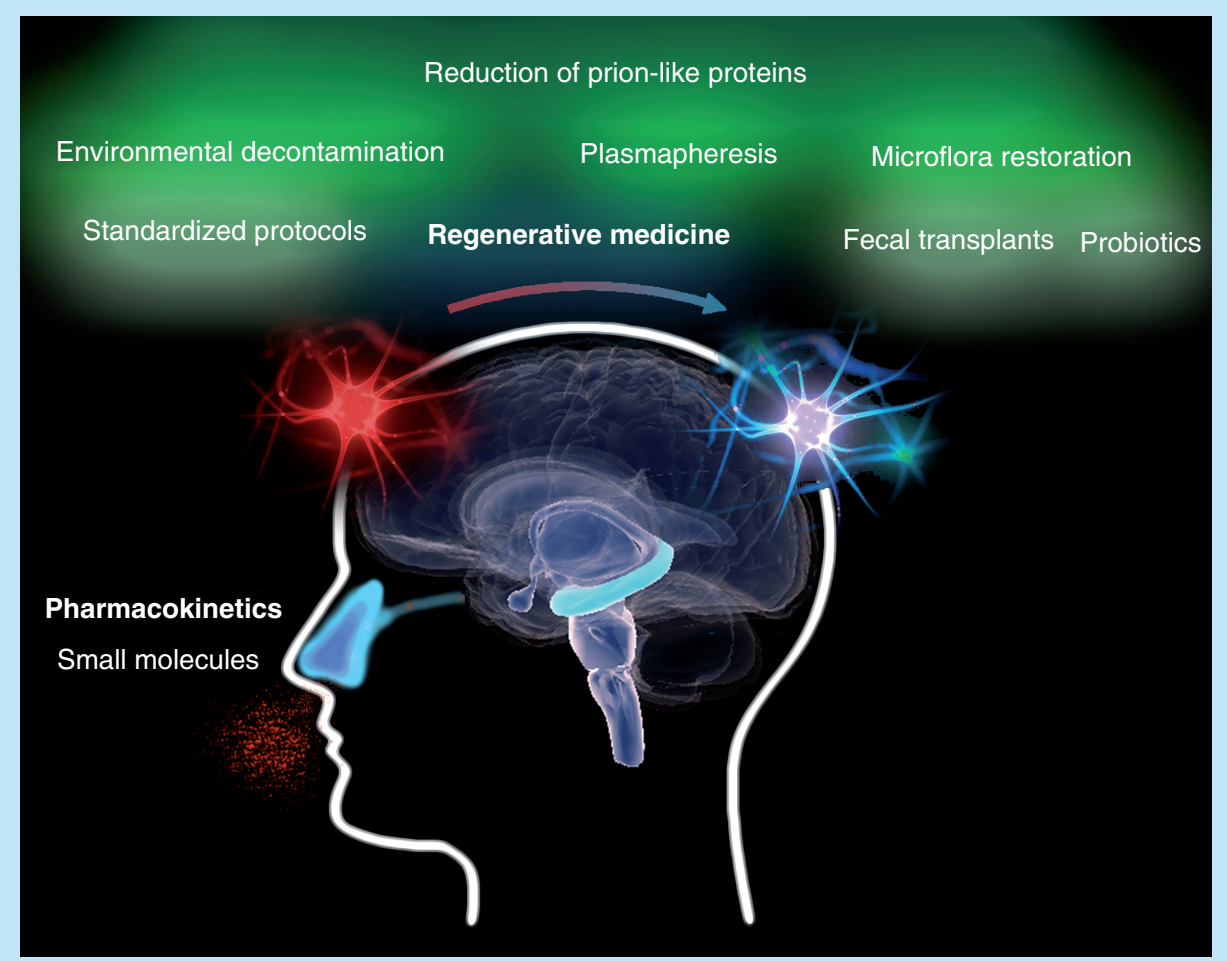

The success of regenerative medicine depends on the restoration of organic homeostasis. Removing prion-like proteins from the body is especially important in sporadic cases of Parkinson's disease, which accounts for $90 \%$ of cases. Small molecules identified as enhancers of neural stem cell regeneration should be tested. Reduced doses could potentially be achieved, and unwanted side effects avoided, by a nasal application.

The increasing prevalence of neurodegenerative diseases in developed countries is a fact recognized by the scientific community. Parkinson's disease (PD) is one of the most insidious, and deserves our attention and efforts. It is probable that more than one therapeutic approach will be needed before we unravel the primary/ultimate cause. One of the most promising treatments is based on regenerative therapy. In the $90 \mathrm{~s}$, the transplantation of fetal cells in patients with PD aroused great expectation, but drawbacks such as the difficulty in obtaining fetal cells, disparity of results and graft-induced dyskinesias slowed down its use. Later, Yamanaka's attempt to produce an unlimited source of stem cells was a success [1]. He applied a breakthrough procedure by introducing four transcriptional factors (Oct3/4, Sox2, Klf4 and c-Myc) with retroviruses in human fibroblasts. The fibroblasts were transformed into cells with similar potential to embryonic stem cells (ESCs); these were called induced pluripotent stem cells (iPSCs). The iPSCs are capable of self-renewal and differentiation into all three germ layers. Since that publication, there has been an avalanche of work in which iPSCs are induced, multiplied, differentiated into different types of nervous cells and implanted both in patients and in murine disease models. Nowadays, hPSCs can be produced from embryonic or adult cells. Significant advances have been made solving some important drawbacks of Yamanaka's strategy; for instance, derived neurons reach functional maturation preventing formation of tumors; the production efficiency has been increased by millions of cells; and transcriptional factors have been reduced, to be substituted by effective small molecules (SMs). However, to date, it is with human embryonic and fetal cells that best clinical outcomes have been achieved, but their use has also been restricted because the extraction process is really complex and it entails important ethical objections. Here a ground-breaking approach must be mentioned that has been developed with human parthenogenetic cells. Cells are derived from human nonfertilized oocytes whose second meiosis is halted resulting in diploid cells [2]. These diploid cells are derived into parthenogenetic neural stem cells (pNSCs) with only maternal chromosomic material. Currently, DOPAminergic neurons derived 
from parthenogenetic pluripotent stem cells (pPSCs) are being tested in clinical trials in Australia [3]. It is too early to know what the results will be; although it could open new research avenues, we still have to learn and see the long-term parthenogenetic cell evolution [4].

For centuries, it was believed that there were no neural progenitor cells (NPCs) in the human CNS. Today, it is clear that in the subventricular zone of the lateral ventricle and the subgranular zone of the hippocampus, there are NPCs that could regenerate the nervous cells and be manipulated 'in vivo' with regenerative purposes [5]. Moreover, it has recently been proven in mice that ependymal cells of the fourth ventricle also have neural stem activity; this supports the idea that the entire lining of the CNS probably has dormant NPCs [6]. Regardless, in addition to fetal and embryonic cells, NPCs are the most studied and promising cells up to date. Theoretically, NPCs have almost unlimited multiplication capacity and are multipotent; that is, they are able to differentiate into several types of nerve cells.

Although this overview will focus on the status of regenerative medicine regarding its application in PD, we should be aware that the available information supports the hypothesis that most insidious neurodegenerative diseases (Alzheimer, Parkinson, Amyotrophic Lateral Sclerosis [ALS], etc) share a common pathogenesis. In most of them, at least one protein with abnormal structure is implicated, (for instance $\beta$-amyloid in Alzheimer, $\alpha$-synuclein in Parkinson and superoxide dismutase in ALS) and cell-to-cell transmission follows the paradigm accepted for prion diseases [7]. That is why they are so-called 'neurodegenerative prion-like diseases'. In some instances, more than one protein is implicated (for instance $\alpha$-synuclein and tau or $\beta$-amyloid and tau). It should be noted that the spectrum is growing, including diseases such as depression. Focusing on synucleinopathies, Prusiner, in 2015, proved that multiple system atrophy (an $\alpha$-synucleinopathy frequently misdiagnosed as PD) is the second prion disease in humans [8]. Moreover, the sporadic cases account for $90 \%$ of all neurodegenerative clinical cases, emphasizing how important it is to consider additional therapeutic approaches besides the regeneration of the damaged tissues.

\section{Multiplication \& differentiation of NSCs}

Compared with other tissues, the nervous system has very limited capacity of regeneration 'in vivo'. Therefore, many studies have been devoted to pursuing the production of NSCs 'in vitro' with regenerative purposes. Due to the extensive scientific literature, we will focus only on relevant studies performed with human cells. Adult cell-derived hiPSCs have been utilized in the majority of research studies, in which the cells later on differentiate into NSCs and finally into mature neurons. The more frequently used cells have been the fibroblast [9], bone marrow mesenchymal stem cells (BM-MCs) [10,11] and umbilical cord cells [9,12]. Nevertheless, other adult cells have also been differentiated such as pericytes of the cerebral cortex, as assayed by Karow et al. in Germany [13], ecto-mesenchymal stem cells from olfactory mucosa in France by Nivet et al. [14], stem cells from carotid body in Spain by Platero-Luengo et al. [15], human urine epithelial cells in China by Cheng et al. [16], stem cells from dental pulp by Zhang et al. [17] and so on.

Since Yamanaka's procedure publication [1], many advances have been made in order to avoid tumor formation and to obtain mature neural cells. In a study published in 2015 by Bardy et al. [18], the authors developed a new culture medium superior to existing media traditionally used for growing and maturing nervous cell lineages. Fully functional glial and neuronal cells were derived from human fibroblasts directly into induced neural cells (iNCs) by using two transcriptional factors, Ascl1 (Mash1) and Ngn2 (Nurr1). The same year, Lee et al. were able to obtain directly iNSCs from human blood cells by using a single transcriptional factor (Oct4) and chemical inhibitors. The iNSCs were postderived into five types of NCs: GABAergic, DOPAminergic, astrocytes, oligodendrocyte and, for the first time, nociceptive sensory neurons [12].

Notwithstanding, the crucial step to avoid the unwanted use of retroviruses was taken earlier in 2014 by Cheng et al. They derived human epithelial cells extracted from urine into NSCs by using a cocktail of three chemicals (Valproic acid VA, Repsox and CHIR 99021) [16]. From the functional standpoint, these SMs are inhibitors; VA inhibits deacetylation of histones, Repsox inhibits glycogen synthase kinase $3 \beta$ (GSK3 $\beta$ ) and CHIR 99021 inhibits EGF. These cells were called chemically induced neural progenitor cells. They obtained cells with an elevated plasticity and a great potential for neuronal conversion by using these chemicals together with hypoxic conditions (mimicking the physiological conditions of oxygen partial pressure of $5 \% \mathrm{O}_{2}$ in the CNS). It deserves to be mentioned that this procedure could be applied to other cells of an epithelial nature such as uterine menstrual cells, which have already been transformed into iPSCs using Yamanaka’s procedure by Ding et al. [19]. In August 2015, the same scientific group obtained the direct conversion of human fibroblasts into mature neuronal cells with four additional SMs: Forskolin, SP600125, GO6983 and Y27632. The majority of these human chemically induced 


\begin{tabular}{|c|c|c|c|}
\hline Cell type & Advantages & Disadvantages & Results \\
\hline hfventral & First clinical studies made & $\begin{array}{l}\text { Ethical concerns } \\
\text { Scarce source }\end{array}$ & Excellent long-term results \\
\hline hESC & $\begin{array}{l}\text { Guaranteed cell source H9WA09 } \\
\text { GMP in place to produce cells of quality } \\
\text { Detailed description of cell markers }\end{array}$ & Immunosuppression treatment & $\begin{array}{l}\text { Functional recovery } \\
\text { No tumorigenicity } \\
\text { Variability }\end{array}$ \\
\hline hiPSC & $\begin{array}{l}\text { Absence of ethical inconvenience } \\
\text { Matched HLA is possible } \\
\text { No immunosuppression treatment } \\
\text { Detailed description of cell markers }\end{array}$ & Time-consuming and high-cost & $\begin{array}{l}\text { Functional recovery } \\
\text { No tumorigenicity } \\
\text { Variability }\end{array}$ \\
\hline hpNSC & $\begin{array}{l}\text { Less ethical objections } \\
\text { Produce neurotrophic agents }\end{array}$ & $\begin{array}{l}\text { Lack of 'bona fide' DOPAminergic } \\
\text { markers }\end{array}$ & Unknown long-term evolution \\
\hline iNC & No pluripotency stage needed & Unknown & Unknown \\
\hline
\end{tabular}

neuron cells (hciNCs) had a glutamatergic nature [20]. In October, they went another important step forward in mice; the direct conversion of astrocytes into four types of neurons: dopaminergic, GABAergic, glutamatergic and motor neurons [21]. It is important to emphasize that astrocytes are very interesting neural cells in terms of regeneration because they actively multiply after brain injury and because they are considered precursor cells of neurons in mammals.

It is clear that the type of starting cells, either fetal or adult, determines the final derived cell type. Whether we use transcriptional factors or chemical inhibitors to dedifferentiate adult cells, the epigenetic memory is specific and determinant of the final result. Regarding this issue, we must mention a suggested multicellular eraser of epigenetic marks, an inhibitor of the BET superfamily proteins (I-BET). The I-BET151 competes with BRD4 (bromodomain-containing protein 4) inhibiting its binding to the super-enhancers of core genes. The results indicate that the addition of I-BET151 in the chemical cocktail resulted in a dramatic increase of functional neurons directly from mice fibroblasts [22]. Therefore, proper chemical SMs acting first as erasers of the epigenetic marks and later as inhibitors of growth factors (EGF, TGF and BMP) or enzymes (protein kinase, GSK3 $\beta$ ) could be used locally in such a way that theoretically the regeneration of the required cell could be achieved.

In terms of efficient production, the number of neurons obtained by Haus et al. in a developed xeno-free culture system was remarkable. They started with hESCs and isolated CD133 $/$ CD34- cells with magnetic sorting. In only 10 days, 300 million hNSCs could be produced and in transplanted mice no teratoma were developed [23].

\section{Production, transplantation \& characterization of precursor DOPAminergic neurons}

Parkinson's was first described in 1817 by James Parkinson, and to the pathognomonic location of the Lewy bodies in the DOPAminergic neurons of hippocampus, described by FH Lewy in 1910. Initially, the degenerated DOPAminergic neurons are confined into the sustantia nigra and the striatum of the hippocampus, a relatively small area of the brain which could be easily substituted. However, it has been more than 24 years since the first transplants of fetal cells were performed in PD patients. To date, the best clinical results obtained in humans are still those using human fetal cells from the ventral mesencephalon [24,25]. The most important obstacle has been the acquisition of fetal tissues together with a high variability in the recovery rates and the development of dyskinesias in treated patients (Table 1).

Optional sources have been sought; among the most promising ones are the precursors of DOPAminergic neurons derived from hPSCs, either from reprogrammed adult cells or from ESCs of early blastocysts. Thanks to many excellent studies, several protocols have been published by which precursor DOPAminergic neurons are produced with high efficiency and proper functionality from hESCs [26,27].

Up to now, fetal cells and hESCs have been used under strict management rules in top research centers, and only in those countries with permissive rules. The derived precursor DOPAminergic neurons from hESCs have been the most studied and the best characterized. We have seen that the line designated H9 (Scottish Centre for Regenerative Medicine, UK) or WA09 (WiCell University of Wisconsin Madison, WI, USA) has been deeply studied [26,27]. It has already been approved by the NIH (MD, USA) and it complies with European rules (National Institute for Biological Standards and Control, UK Stem Cell Bank); even a commercial brand offers this H9WA09 


\begin{tabular}{|c|c|c|c|}
\hline Cell type & Clinical trials & Country/Leaders & Consortium/Company/University \\
\hline hfC & $\begin{array}{l}\text { NCT001898390 } \\
2010-2021\end{array}$ & $\begin{array}{l}\text { UK, Sweden } \\
\text { Dr Barker RA Dr Parmar M }\end{array}$ & TRANSEURO GFORCE \\
\hline $\mathrm{hfC}$ & $\begin{array}{l}\text { NCT03128450 } \\
2017\end{array}$ & $\begin{array}{l}\text { China } \\
\text { Dr Chun-Feng Liu }\end{array}$ & Second Affiliated Hospital of Soochow University \\
\hline hESC & $\begin{array}{l}\text { NCT03119636 } \\
2017-2020\end{array}$ & $\begin{array}{l}\text { China } \\
\text { Dr Qi Zhou }\end{array}$ & Chinese Academy of Sciences \\
\hline hiPSC & $\begin{array}{l}\text { R000038278 } \\
2018\end{array}$ & $\begin{array}{l}\text { Japan } \\
\text { Dr Jun Takahashi }\end{array}$ & $\begin{array}{l}\text { Center for iPS Cell Research and Application, Kyoto } \\
\text { University }\end{array}$ \\
\hline UCMSC & $\begin{array}{l}\text { NCT03550183 } \\
2018\end{array}$ & $\begin{array}{l}\text { China } \\
\text { Dr Shengjun An }\end{array}$ & $\begin{array}{l}\text { Newtherapy Blo-Pharma Technology Co., Ltd } \\
\text { Shijiazhuang, Hebei }\end{array}$ \\
\hline ASC & $\begin{array}{l}\text { NCT02184546 } \\
2014-2018\end{array}$ & USA & StemGenex, San Diego, CA \\
\hline BMSC & $\begin{array}{l}\text { NCT01446614 } \\
\text { 2011- }\end{array}$ & China & Hospital Guanjzhou, Guanjdong \\
\hline BMSC & $\begin{array}{l}\text { NCT03297177 } \\
\text { 2016- }\end{array}$ & $\begin{array}{l}\text { USA } \\
\text { MD Stem Cells }\end{array}$ & $\begin{array}{l}\text { The Healing Institute Margate, FL, USA } \\
\text { Euro-Arabian Hospital Dubai, Sharjah, United Arab } \\
\text { Emirates }\end{array}$ \\
\hline BMSC & $\begin{array}{l}\text { NCT02611167 } \\
2017-2019\end{array}$ & $\begin{array}{l}\text { USA } \\
\text { Dr Mya Schiess }\end{array}$ & $\begin{array}{l}\text { The University of Texas Health Science Center at Houston } \\
\text { Houston, TX }\end{array}$ \\
\hline hpNSC & $\begin{array}{l}\text { NCT02452723 } \\
2016-2020\end{array}$ & $\begin{array}{l}\text { Australia, Royal Melbourne Hospital, } \\
\text { Parkville }\end{array}$ & International Stem Cell Corporation, Carlsbad, CA \\
\hline
\end{tabular}

Source NIH https://clinicaltrials.gov/

ASC: Adipose stem cell; BMSC: Bone marrow mesenchymal stem cell; hfC: Human fetal cell; hpNSC: Human parthenogenetic neural stem cell; hESC: Human embryonic stem cell; UCMSC: Umbilical cord mesenchymal stem cell.

line. Theoretically, the unlimited production of precursor DOPAminergic neurons could be possible using these hESCs lines. Therefore, if no more embryos are needed one could wonder what ethical objections there could be in expanding and differentiating the hPSCs into precursor DOPAminergic neurons.

Fortunately for patients with sporadic PD, the first estimations of the number of cells that need to be replaced are very low, approximately 'hundred thousand' cells would be sufficient for one patient. Obviously, these numbers are low for 'in vitro' culture systems and few laboratories would be required to cover the needs of PD patients in each country.

Regarding DOPAminergic precursors derived from hiPSCs, the results of preclinical studies made in a monkey model for PD were published in 2017. Takahashi et al. [28] reported that the DOPAminergic cells survived for at least 2 years and formed connections with the monkey brain cells. In the treated monkeys, there was a gradual onset of motor functions and no tumor formation was reported. However, the results in terms of survival of DOPAminergic, neurons were highly variable, suggesting that there are still unknown factors in the hiPSC lines that should be characterized before clinical trials can be made.

We are carefully looking at the ongoing clinical trials worldwide (Table 2). In China, they have recruited PD patients for the transplantation of matched human leukocyte antigen (HLA) cells derived from hESCs. In Australia, ISCO started clinical trials with DOPAminergic neurons derived from human parthenogenetic cells. Some drawbacks have been pointed out regarding the use of parthenogenetic cells: these cells express PAX6 factor which have not been identified 'bona fide' ventral midbrain progenitors DOPAminergic neurons [27,28]. There are great expectations ahead, but the hurry and commercial interests need to be put in second place when the hopes of millions of patients are at stake. We hope to see PD be the first neurodegenerative disease to be cured thanks to regenerative medicine.

\section{Rejection of transplanted cells}

Single cell transcriptome studies have recently revealed that human fetal cells extracted at 16-18 weeks of gestation are not rejected in part due to the absence of the major histocompatibility complex MHC type I. Unfortunately, the results of this study imply that the CNS is not as immunologically inert as we thought, and that ESCs hPSCs could be very distant from adult neurons [29]. The union of the NSCs with the extracellular matrix of the recipient patient, without any doubt, must be important in the rejection or not of the donor NSCs. The extracellular matrix is in contact with the glycocalyx of NSCs and very little is known about how these components are associated in 
the human brain. Studies concerning glycoconjugates (glycoproteins or glycolipids) of human NPC's glycocalyx are almost absent.

The important role of the chemical structure of carbohydrates in the CNS is illustrated by experiments made in chickens with intracerebral injections of 2-deoxigalactose. The 2-deoxigalactose induces amnesia, which is reverted when coinjected with galactose [30]. As far as we know, only in rodents have the patterns of specific glycans in CNS been studied. All types of neuronal cells in SG and SV zones could be identified with labeled lectins [31]. In fact, also by using lectins, Hamanoue et al. isolated NPCs and deciphered the roles of N-acetylglucosamine and its enzymes on NPC functions, such as cellular migration and immunity [32,33]. Taken together, all these facts stress how important the implication of glycoconjugates and their carbohydrates are in the interneuronal connections of the CNS.

Therefore, if we want to advance into successful tissue replacements more glycobiology studies will be needed to support future glyco-engineering approaches [30].

\section{From bench to bed}

There are translational prospects for neurodegenerative diseases, for example, from the studies made in China. The astrocytes localized in the SG and SV zones behave as neurogenic precursor cells in adult mammals [34]. This peculiar characteristic makes them ideal targets for regenerative use in vitro and in vivo. In order to convert astrocytes into neuronal cells, Cheng et al. dissected the essential chemicals used in their initial work from three (valproic acid, Repsox and CHIR 99021) to two SMs (valproic acid and Repsox). Then, they skillfully replaced SMs by drugs already authorized, which should simplify the authorization process for the new pharmacological indications. Valproic acid, an antiepileptic drug (inhibitor of histones deacetylases), and Tranilast, an antiallergic drug (inhibitor of EGF), were used 'in vitro' with successful results in astrocytes of adult mice [21]. The authors suggested the possibility of applying these chemicals directly in patients with PD. From a translational perspective, this could be a 'from bench to bed' study. Therefore, we would expect that the local treatments with valproic acid and tranilast could favor the differentiation of human astrocytes into neurons whenever required.

We have to point out that the use of valproic acid in patients with PD could add other advantages apart from its important antidepressant therapeutic effect, that is, its positive effect on the expression of galectin-1 [35]. Galectin$1 \beta$ (galactose-binding lectin) is known as a neuroprotective agent and promotor of the axonal regeneration [36], emphasizing again the important role that the galactose and galectin-1 could have in the functional connection between neurons and extracellular matrix. On the other hand, strong evidences support that $\alpha$-synuclein is propagated by exocytosis-endocytosis from cell to cell. Importantly, the receptor implicated in the endocytosis of pathogenic $\alpha$-synuclein fibrils ( $\mathrm{N}$-methyl-D-aspartate receptor NMDA receptor) was competitively inhibited by galectin-1 in hNSCs. In fact, it has been proven that human BM-MCs produce galectin-1 which, in turn, behaves as a competitive protein with $\alpha$-synuclein in cocultured hNSCs. Moreover, in a parkinsonian mouse model, galectin-1 improved neuron survival and motor function [37]. Studies in Alzheimer's models, both in vitro and in vivo have also supported the role of the NMDA receptor in the cellular internalization of $\beta$-amyloid fibrils. In truth, both increased $\beta$-amyloid clearance and survival of hippocampal neurons were seen when BM-MCs were injected in the tail vein of mice [38], probably through the same mechanism described for $\alpha$-synuclein. Therefore, in $\alpha$-synucleinopathies as well as in diseases with $\beta$-amyloid fibrils formation, pharmacokinetics studies of SMs deserve to be conducted.

Chronic systemic treatments with VPA have reported some worsening of Parkinson's symptoms. These cases are reversible when the treatment ceases. Therefore, to undertake pharmacokinetic studies of local application would allow decreased doses, the overcoming of unwelcome secondary effects and, hopefully, the promotion of NSCs present in the hippocampus. In order to apply the treatments with SMs, one of the best routes could be through the nose. Anatomically, the olfactory bulb is very close to the roof of the nasal cavity and functionally, it is connected with the hippocampus. In a recent study made by Alvarez-Buylla et al., the authors discovered that in the subventricular zone of the lateral ventricle, the NSCs or type B1 cells divided symmetrically giving rise to an asymmetric population of $20 \%$ self-renewal NSCs and $80 \%$ differentiated neurons [39]. We wonder if we could reverse these percentages in PD patients. We also know, thanks to the work made by Chen $e$ al. in 2017, that the specific inhibition of GSK3 $\beta$ favors NSC self-renewal while the inhibition of GSK3 $\alpha$ favors neuronal differentiation in mouse ESCs [40]. Therefore, if this holds true in humans, it could be possible to use nose instillations of GSK3 $\beta$ inhibitors or other SMs in order to increase the number of NSCs. To end this exposition on the state of the art of nervous tissue replacement, the good news is that the results of the transplantation of NSCs derived from human fetuses into Parkinson's patients have been more than encouraging. 24 years after implantation of fetal ventral 
cells, which were injected in the putamen, there was a complete recovery of the innervation with still functional dopaminergic neurons. Motor symptom recovery and withdrawal of the treatment with LDOPA resulted, and following deaths were not owing to the disease $[41,42]$.

\section{Future perspective}

Today, human ESCs are becoming available in many countries around the world [43-45]. Agreements on robust protocols for multiplication and differentiation of ESCs and iPSCs, good practice codes and standards, disclosed specs for the starting somatic cells, and robust cryopreservation procedures of cells $[45,46]$ and so on, should be reached as soon as possible. This will assure a fruitful outcome for the enormous efforts that are being made in this research field around the world. In fact, a few European countries together with USA and Japan have formed a GForce-PD consortium, which has already begun working in this direction and will start very soon with human clinical trials [47].

We must not forget that $\alpha$-synuclein prions exist in patients with multiple system atrophy, that $\alpha$-synuclein is present in organic fluids and in other parts of the body besides the brain, and finally, that in some patients other prion-proteins could coexist. Therefore, we should take important sanitary actions because prion proteins do not respond to standard decontamination procedures. Generally, in laboratories and hospitals around the world, standard conditions used for sterilization in an autoclave are $120^{\circ} \mathrm{C}$ for $20 \mathrm{~min}$; these are not enough to decontaminate prions. Therefore, we strongly recommend strict protocols for decontamination of prion-like protein, especially in the use of surgical material which should be new for each patient in clinical trials.

Some other clinical therapies have been suggested such as the reduction of the levels of pathological proteins with plasmapheresis [48] or the restoration of intestinal leaking with fecal transplants [49,50]. Although ideally these treatments should be done before regenerative therapy, unfortunately little or nothing is known about their efficacy and safety. If we do not take into consideration all these precautions, transplanted cells could be negatively affected by the presence of prion-like proteins in the recipient patients, endangering their recovery or masking good results.

There is a fine compromise between 'rejection' and 'teratoma formation'; the less differentiated a cell is, more probability exists that a teratoma will develop yet there is a lower probability of rejection. Regarding 'teratoma formation' many technical advances have been made since Yamanaka's first studies. Almost all scientists already claim that their cells have not developed tumors in long-term trials. To circumvent the 'rejection' either an immunosuppressive treatment should be applied or compatible grafts should be used. Almost all clinical studies have included an immunosuppressive treatment, except in the trial made with autologous iPSC from which we still do not know the results.

Unfortunately, there is still a high variability in the recovery rate in the studies made with DOPAminergic precursors derived from ESC and hiPSC (Table 1). Nowadays, autologous hiPSCs derived from patients with genetic Parkinson's cannot be used. Hopefully, in the near future, different types of stem cells will be produced and used in agreement with the pathogenesis of PD.

Certainly, there is still a way to walk before nervous tissue replacement therapies are fully implemented in daily clinical practice. Meanwhile, 'in vitro' studies should focus on the key elements for human embryonic and fetal cell transplants to be successful. In the case of PD, the joint efforts of many researchers from around the world are bringing us closer.

Executive summary

- Different strategies for obtaining neural stem cells are being tested worldwide.

- It is probable that a cure will need more than one therapeutic approach.

- Pharmacokinetic studies should be performed with small molecules.

- Additional therapies (for example fecal transplant, microflora reconstitution) could help to restore endogenous physiological functions.

- Protocols of prion-like proteins decontamination should be thoroughly applied. 
Financial \& competing interests disclosure

The author is a state employee of the Spanish government's Ministry of Science, Innovation and Universities. The author has no other relevant affiliations or financial involvement with any organization or entity with a financial interest in or financial conflict with the subject matter or materials discussed in the manuscript apart from those disclosed.

No writing assistance was utilized in the production of this manuscript.

Open access

This work is licensed under the Creative Commons Attribution 4.0 License. To view a copy of this license, visit http://creativecomm ons.org/licenses/by/4.0/

\section{References}

Papers of special note have been highlighted as: $\bullet$ of interest; $\bullet \bullet$ of considerable interest

1. Yamanaka S. A fresh look at iPS cells. Cell 137, 13-17 (2009).

-• First human reprogrammed cells (hiPSC) with transcriptional factors.

2. Revazova ES, Turovets NA, Kochetkova OD et al. Patient-specific stem cell lines derived from human parthenogenetic blastocysts. Cloning Stem Cells 9, 432-449 (2007).

- Parthenogenetic human neural stem cells.

3. Gonzalez R, Garitaonandia I, Crain A et al. Proof of concept studies exploring the safety and functional activity of human parthenogenetic-derived neural stem cells for the treatment of PD. Cell Transplant. 24(4), 681-690 (2015).

- Parthenogenetic human neural stem cells.

4. Wilmut I. Embryo stem cells from parthenotes and embryos produced by nuclear transfer the distintion between them and their potential value in cell theraphy. Cloning Stem Cells 9, 291-292 (2007).

5. Gage FH. Stem cells of the central nervous system. Curr. Opin. Neurobiol. 8, 671-676 (1998).

6. Luo Y, Coskun V, Liang A et al. Single-cell transcriptome analyses reveal signals to activate dormant neural stem cells. Cell 161(5), 1175-1186 (2015).

7. Guo JL, Lee VM. Cell-to-cell transmission of pathogenic proteins in neurodegenerative diseases. Nat. Med. 20, 130-138 (2014).

-. Prion-like protein involvement in neurodegenerative diseases.

8. Prusiner SB, Woerman AL, Mordes DA et al. Evidence for $\alpha$-synuclein prions causing multiple system atrophy in humans with parkinsonism. Proc. Natl Acad. Sci. USA 112(38), E5308-5317 (2015).

-• Prion-like protein involvement in neurodegenerative diseases.

9. Pulecio J, Nivet E, Sancho-Martinez I et al. Conversion of human fibroblasts into monocyte-like progenitor cells. Stem Cells 32, 2923-2938 (2014).

- Production of neural stem cells (NSCs) from hiPSC.

10. Park HJ, Lee PH, Bang OY, Lee G, Ahn YH. Mesenchymal stem cells therapy exerts neuroprotection in a progressive animal model of Parkinson's disease. J. Neurochem. 107, 141-151 (2008).

- Production of NSC from hiPSC.

11. Biju KC, Santacruz RA, Chen C et al. Bone marrow-derived microglia-based neurturin delivery protects against dopaminergic neurodegeneration in a mouse model of Parkinson's disease. Neurosci. Lett. 535, 24-29 (2013).

- $\quad$ Production of NSC from hiPSC.

12. Lee JH, Mitchell RR, McNicol JD et al. Single transcription factor conversion of human blood fate to NPCs with CNS and PNS developmental capacity. Cell Rep. 11(9), 1367-1376 (2015).

- Production of NSC from hiPSC.

13. Karow M, Sánchez R, Schichor $\mathrm{C}$ et al. Reprogramming of pericyte-derived cells of the adult human brain into induced neuronal cells. Cell Stem Cell 11, 471-476 (2012).

- Production of NSC from hiPSC.

14. Nivet E, Vignes M, Girard SD et al. Engraftment of human nasal olfactory stem cells restores neuroplasticity in mice with hippocampal lesions. J. Clin. Invest. 121, 2808-2820 (2011).

- Production of NSC from hiPSC.

15. Platero-Luengo A, González-Granero S, Durán $\mathrm{R}$ et al. An $\mathrm{O}_{2}$-sensitive glomus cell-stem cell synapse induces carotid body growth in chronic hypoxia. Cell 156, 291-303 (2014).

- Production of NSC from hiPSC.

16. Cheng L, Hu W, Qiu B et al. Generation of neural progenitor cells by chemical cocktails and hypoxia. Cell Res. 24, 665-679 (2014).

-. Production of NSC with small molecules. 
17. Zhang J, Lu X, Feng G et al. Chitosan scaffolds induce human dental pulp stem cells to neural differentiation: potential roles for spinal cord injury therapy. Cell Tissue Res. 366(1), 129-142 (2016).

- $\quad$ Production of neural stem cell (NSC) from hiPSC.

18. Bardy C, van den HM Eames $\mathrm{T}$ et al. Neuronal medium that supports basic synaptic functions and activity of human neurons in vitro. Proc. Natl Acad. Sci. USA 112, E2725-E2734 (2015).

19. Ding Z, Sui L, Ren R et al. A widely adaptable approach to generate integration-free iPSCs from non-invasively acquired human somatic cells. Protein Cell 6, 386-389 (2015).

20. Hu W, Qiu B, Guan W et al. Direct conversion of normal and alzheimer disease human fibroblast. Cell Stem Cell 17(2), 204-212 (2015).

21. Cheng L, Gao L, Guan W et al. Direct conversion of astrocytes into neuronal cells by drug cocktail. Cell Res. 25, 1269-1272 (2015).

-. Production of NSC with small molecules.

22. Li X, Zuo X, Jing J et al. Small-molecule-driven direct reprogramming of mouse fibroblasts into functional neurons. Cell Stem Cell 17(2), 195-203 (2015).

-. Production of NSC with small molecules.

23. Haus DL, Nguyen HX, Gold EM et al. CD133- enriched xeno-free human embryonic-derived neural stem cells expand rapidly in culture and do not form teratomas in immunodeficient mice. Stem Cell Res. 13, 214-226 (2014).

24. Hallett PJ, Cooper O, Sadi D, Robertson H, Mendez I, Isacson O. Long-term health of dopaminergic neuron transplants in Parkinson's disease patients. Cell Rep. 7, 1755-1761 (2014).

25. Li W, Englund $\mathrm{E}$, Widner $\mathrm{H}$ et al. Extensive graft-derived dopaminergic innervation is maintained 24 years after transplantation in the degenerating parkinsonian brain. Proc. Natl Acad. Sci. USA 113, 6544-6549 (2016).

-. Long-term results in human using transplanted fetal cells.

26. Kriks S, Shim JW, Piao J et al. Dopamine neurons derived from human ES cells efficiently engraft in animal models of Parkinson's disease. Nature 480, 547-551 (2011).

-• DOPAminergic precursors derived from hESC and hiESC.

27. Kirkeby A, Grealish S, Wolf DA et al. Generation of regionally specified neural progenitors and functional neurons from human embryonic stem cells under defined conditions. Cell Rep. 1, 703-714 (2012).

-• DOPAminergic precursors derived from human embryonic stem cells (hESC) and hiESC.

28. Kikuchi T, Morizane A, Doi D et al. Human iPS cell-derived dopaminergic neurons function in a primate Parkinson's disease model. Nature 548(7669), 592-596 (2017).

-• DOPAminergic precursors derived from hESC and hiESC.

29. Darmanis S, Sloan SA, Zhang Y et al. A survey of human brain transcriptome diversity at the single cell level. Proc. Natl Acad. Sci. USA 112(23), 7285-7290 (2015).

30. Griffin ME, Hsieh-Wilson LC. Glycan engineering for cell and developmental biology. Cell Chem. Biol. 23, 108-121 (2016).

31. Kitada M, Kuroda Y, Dezawa M. Lectins as a tool for detecting neural stem/progenitor cells in the adult mouse brain. Anat. Rec. 294(2), 305-321 (2011).

32. Hamanoue M, Okano H. Cell surface N-glycans-mediated isolation of mouse neural stem cells. J. Cell. Physiol. 226, 1433-1438 (2011).

33. Hamanoue M, Ikeda Y, Ogata T, Takamatsu K. Predominant expression of N-acetyl glucosaminyl transferase V (GnT-V) in neural stem/progenitor cells. Stem Cell Res. 14, 68-78 (2015).

34. Lim DA, Alvarez-Buylla A. The adult ventricular-subventricular zone (V-SVZ) and olfactory bulb (OB) neurogenesis. Cold Spring Harb. Perspect. Biol. 8(5), 1-33 (2016).

35. Camby I, Le Mercier M, Lefranc F, Kiss R. Galectin-1: a small protein with major functions. Glycobiology 16, 137R-157R (2006).

36. Miura T, Takahashi M, Horie H, Kurushima H, Tsuchimoto D. Galectin-1beta, a natural monomeric form of galectin-1 lacking its six amino-terminal residues promotes axonal regeneration but not cell death. Cell Death Differ. 11, 1076-1083 (2004).

37. Oh SH, Kim HN, Park HJ et al. Mesenchymal stem cells inhibit transmission of a-synuclein by modulating clathrin-mediated endocytosis in a parkinsonian model. Cell Rep. 14, 835-849 (2016).

38. Shin JY, Park HJ, Kim HN et al. Mesenchymal stem cells enhance autophagy and increase B-amyloid clearance in Alzheimer disease models. Autophagy 10, 32-44 (2014).

39. Obernier K, Cebrian-Silla A, Thomson M et al. Adult neurogenesis is sustained by symmetric self-renewal and differentiation. Cell Stem Cell 22(2), 221-234 (2018).

40. Chen X, Wang R, Liu X et al. Chemical-genetic approach reveals the distinct roles of GSK3 $\alpha$ and GSK3 $\beta$ in regulating embryonic stem cell fate. Dev. Cell. 43(5), 563-576 (2017).

41. Hallett PJ, Cooper O, Sadi D, Robertson H, Mendez I, Isacson O. Long-term health of dopaminergic neuron transplants in Parkinson's disease patients. Cell Rep. 7, 1755-1761 (2014). 
42. Li W, Englund $\mathrm{E}$, Widner $\mathrm{H}$ et al. Extensive graft-derived dopaminergic innervation is maintained 24 years after transplantation in the degenerating parkinsonian brain. Proc. Natl Acad. Sci. USA 113, 6544-6549 (2016).

43. Kirkeby A, Nolbrant S, Tiklova $\mathrm{K}$ et al. Predictive markers guide differentiation to improve graft outcome in clinical translation of hESCs-based therapy for parkinson's disease. Cell Stem Cell 20, 1-14 (2016).

44. Tsukamoto A, Uchida N, Capela A, Gorba T, Huhn S. Clinical translation of human neural stem cells. Stem Cell Res. Ther. 4, 102 (2013).

45. Fortin JM, Hassan A, Zheng T et al. Transplantation of defined populations of differentiated human neural stem cell progeny. Sci. Rep. 6, 1-13 (2016)

46. Wakeman DR, Hiller BM, Marmion DJ et al. Cryopreservation maintains functionality of human iPSC dopamine neurons and rescues Parkinsonian phenotypes In Vivo. Stem Cell Rep. 9(1), 149-161 (2017).

47. Barker RA, Parmar M, Studer L, Takahashi J. Human trials of stem cell-derived dopamine neurons for Parkinson's Disease: dawn of a new era. Cell Stem Cell 21, 569-573 (2017).

48. Cuberas-Borrós G, Roca I, Boada M et al. Longitudinal neuroimaging analysis in mild-moderate Alzheimer’s disease patients treated with plasma exchange with 5\% human albumin. J. Alzheimers Dis. 61(1), 321-332 (2018).

49. Mangalam A, Shahi SK, Luckey D et al. Human gut-derived commensal bacteria suppress CNS inflammatory and demyelinating disease. Cell Rep. 20(6), 1269-1277 (2017).

50. Forsyth CB, Shannon KM, Kordower JH et al. Increased intestinal permeability correlates with sigmoid mucosa alpha-synuclein staining and endotoxin exposure markers in early Parkinson's disease. PLoS ONE 6(12), e28032 (2011). 